${ }^{*}$ Department of Psychiatry, Indiana University School of Medicine, Indianapolis 46202, USA.

${ }^{*}$ Neuroscience Research Division, Lilly Research Laboratories, Eli Lilly and Company, Lilly Corporate Center, Indianapolis 46285, USA.

Correspondence to D.T.W. e-mail:

dtwongindy@iquest.net doi:10.1038/nrd1821

Published online 24 August 2005

\title{
THE DISCOVERY OF FLUOXETINE HYDROCHLORIDE (PROZAC)
}

\author{
David T. Wong*, Kenneth W. Perry ${ }^{*}$ and Frank P. Bymaster \\ Abstract | In the early 1970s, evidence of the role of serotonin (5-hydroxytryptamine or 5-HT) in \\ depression began to emerge and the hypothesis that enhancing 5-HT neurotransmission would \\ be a viable mechanism to mediate antidepressant response was put forward. On the basis of \\ this hypothesis, efforts to develop agents that inhibit the uptake of 5-HT from the synaptic cleft \\ were initiated. These studies led to the discovery and development of the selective serotonin- \\ reuptake inhibitor fluoxetine hydrochloride (Prozac; Eli Lilly), which was approved for the \\ treatment of depression by the US FDA in 1987. Here, we summarize this research and discuss \\ the many challenges that we encountered during the development of fluoxetine hydrochloride, \\ which has now been widely acknowledged as a breakthrough drug for depression.
}

\section{CASE HISTORY (C)}

"Neuroscience is a young field. During its early years, there was little basis for hypotheses except of the vaguest sort. What good would our hypotheses have been without some fundamental, descriptive information about the brain — ranging from its anatomical organization and connections to its electrical properties and the existence of particular chemicals and signalling mechanisms within it?"

Huda Akil, President, Society For Neuroscience, 2003

Fluoxetine hydrochloride (3-( $p$-trifluoromethylphenoxy)- $\mathrm{N}$-methyl-3-phenylpropylamine $\mathrm{HCl}$; Lilly (LY) 110140) was first described in a scientific journal in 1974 as a selective serotonin (5-hydroxytryptamine or 5-HT)-uptake inhibitor ${ }^{1,2}$. After the initial publications, it took more than 16 years - during which time many challenges arose - to complete the development of fluoxetine hydrochloride (Prozac; Eli Lilly), which culminated in its approval for the treatment of depression by the US FDA on 29 December 1987. Fluoxetine hydrochloride was an early member of a new class of antidepressant drugs (and the first to be introduced in the United States) that are commonly known as selective serotonin-reuptake inhibitors (SSRIs). These have since become the most widely prescribed antidepressants.
Although the core scientists who were involved in the project to develop fluoxetine never doubted that it would become an antidepressant drug, others were unsure ${ }^{1}$. Market analysis showed that the revenue from antidepressant sales was valued at less than US $\$ 200$ million in the first 8 months of 1975 and the market was considered to be satisfied. So, it would be presumptive to claim that we anticipated the wide acceptance of Prozac by both physicians and patients. Neither did we foresee that its pale-green and light-yellow capsule would appear on the cover of Newsweek (26 March 1990), which described it as: "A breakthrough drug for depression". Fortune magazine named it as one of the "Pharmaceutical Products of the Century" (22 November 1999) and by 2002 (1 year after Lilly's marketing exclusivity expired) Prozac had been prescribed to more than 40 million patients worldwide with total sales of US $\$ 22$ billion; the peak annual sales were US $\$ 2.8$ billion in 1998.

There have been several review articles on the pharmacology $y^{3-5}$ and clinical uses ${ }^{6-8}$ of fluoxetine hydrochloride; however, so far, apart from one brief account ${ }^{9}$, the story of its development has not been published. Here, we record the 'case history' of fluoxetine hydrochloride and discuss the many challenges that were overcome during its $\sim 16$-year journey to approval. 


\section{Early impetus}

The treatise entitled 'The Structure and Function of Nervous Tissue, Volume III: Biochemistry and Disease' (edited by Bourne) provided the 'state of the art' knowledge, in 1969, of the biochemical and neurochemical processes of the $\mathrm{CNS}^{10}$. This volume attracted attention owing to its insightful and informative chapters, including the opening chapter on the subcellular fractionation of the nervous tissue separating brain mitochondria from nerve endings (synaptosomes; BOX 1) ${ }^{11-15}$, and the distribution of neurotransmitters and their synthetic enzymes (contributed by Whittaker), along with chapters on the synthesis of acetylcholine, glutamate and aspartate, as well as 5-HT (contributed by Hebb and Morris, Schoffeniels and Page, respectively). In the chapter on 5-HT, Page elaborated the processes of synthesis, storage, release, breakdown and uptake, which met the criteria of a putative neurotransmitter, along with the pharmacological consequences on brain levels of 5-HT. We later presented the pharmacological evidence that led to the search for inhibitors that are targeted selectively to the uptake of 5-HT. It will become clear that the approach of identifying the uptake of 5-HT as the target for antidepressant drug discovery was initially independent from another antidepressant development project, which screened compounds that produced behavioural and physiological responses comparable to those of the tricyclic antidepressant (TCA) drugs. Moreover, the reliance on a biochemical approach using synaptosomal preparations (BOX 1) to discover centrally acting drugs in the Lilly Research Laboratories in 1971 began before the advent of radioligand binding to the recognition sites of ligands, including opiates and benzodiazepines, in the brain.

\section{5-HT uptake and pharmacology}

Since the late 1960s, the processes involved in the synthesis, degradation, storage, uptake and release of 5-HT have been characterized ${ }^{16}$, as shown in the 5-HTcontaining neuron depicted in FIG. 1. The figure also illustrates the presently known receptor subtypes that recognize 5-HT as a natural ligand. 5-HT was identified as a factor in serum that is responsible for producing the vasoconstriction of smooth muscle preparations ${ }^{17}$. Most importantly, 5-HT was also found to be present in brain tissues shortly thereafter ${ }^{18}$. Except for the specific rate-limiting enzyme, tryptophan hydroxylase, the other biochemical processes were considered to be common to those for the two better established monoaminergic neurotransmitters, dopamine (DA) and noradrenaline (NA), which are collectively known as catecholamines ${ }^{19}$. Histochemical studies uncovered distinct and separate distributions of neurons and neuronal fibres for an individual monoamine, and gave support to the presence of separate 5-HT-containing neuronal fibres from those containing the two catecholaminergic neurotransmitters in the brain ${ }^{20-22}$. These seminal findings led us to conclude that the 5 -HT-containing neurons were indeed distinct from those containing DA and $\mathrm{NA}^{23-25}$.

\section{Inhibitors of monoamine uptake}

The drugs that were known to be effective for the treatment of depression during the 1960s and 1970s were inhibitors either of the enzyme monoamine oxidase (MAO), which degraded the monoamines, or of the uptake of monoamines ${ }^{26-29}$. Pharmacological studies of monoamine uptake using cardiovascular preparations led to the seminal concept that the TCA imipramine and its metabolite desipramine owed their clinical efficacy to inhibiting the uptake of monoamines and, in turn, enhanced monoaminergic neurotransmission by NA in particular ${ }^{30,31}$. Therefore, the inhibition of MAO or NA uptake would increase NA availability and, consequently, the neurotransmission of NA; the efficacy of drugs that had these effects provided support to the monoamine or catecholamine hypothesis of depression, which proposed that this disorder results from a deficiency in monoaminergic function ${ }^{26,27,29}$.

Imipramine, and its tertiary-amine-containing congeners amitriptyline and clomipramine, were found to more effectively inhibit the uptake of 5-HT than that of NA both in vitro and in vivo in the $\mathrm{CNS}^{22,32,33}$. Based on the clinical observations made by colleagues in psychiatry, Carlsson and his collaborators proposed that the inhibition of 5-HT uptake might contribute to the mood-elevating action of the tertiary-amine-containing TCAs ${ }^{34,35}$. The corresponding secondary-amine-containing tricyclic compounds - namely, desipramine, nortriptyline and desmethylclomipramine - on the other hand, are more potent inhibitors of the uptake of NA than of 5-HT. Inhibition of NA uptake was thought to be more likely to be associated with the drive actions of the secondary-amine-containing TCAs ${ }^{34,36}$.

In addition to the above histochemical and pharmacological studies, the co-authors were intrigued by data pointing to the possible involvement of 5-HT in depression, as discussed in the treatise of Weil-Malherbe and Szara $^{29}$. Levels of 5-HT and its metabolite 5-hydroxyindoleacetic acid (5-HIAA) in autopsy samples of the hind-brain of depressed patients who had committed suicide were found to be lower than those from victims of sudden death or coronary occlusion ${ }^{37,38}$, although no significant difference was reported by another group of investigators ${ }^{39}$. There were also reports of low levels of 5-HIAA in the bodily fluids of depressed patients, but the interpretation of these findings was considered to be even more complicated. Moreover, the antidepressant effects of MAO inhibitors seemed to be enhanced by combining them with tryptophan or 5-hydroxytryptophan, which are precursors of 5-HT synthesis ${ }^{40-42}$. These experimental findings led to the suggestion that indolamines, and 5-HT in particular, were involved in depression and, therapeutically, could be as important as $\mathrm{NA}^{29}$. We summarized these tenuous findings in the first publication about LY110140 (REF. 1), which was later named fluoxetine.

Based on the aforementioned information, studies of 5-HT and NA uptake in brain tissues using $\left[{ }^{3} \mathrm{H}\right]-5-\mathrm{HT}$ and $\left[{ }^{3} \mathrm{H}\right]-\mathrm{NA}$, respectively, as substrates were initiated in the Lilly Research Laboratories in early 1971. The 


\section{Box 1 | Synaptosomes and drug discovery research}

Subcellular fractionation of a brain homogenate in a sucrose gradient by the differential centrifugation technique yielded fractions that contained particles that were anatomically identified as 'pinched-off' nerve endings ${ }^{11,12}$. Isolated nerve endings, which were also previously known as 'synaptosomes' or 'miniature cells', were found to possess the biochemical apparatus for glucose metabolism and mitochondrial substrate oxidation. In addition, neurotransmitter substances, including acetylcholine, and the monoamines, dopamine (DA), noradrenaline (NA) and serotonin (5-hydroxytryptamine or 5-HT), were present ${ }^{12}$.

Synaptosomes were also described as having the capacity for monoamine synthesis, potassium-induced neurotransmitter release and the clearance of neurotransmitters by uptake processes.

The procedure for preparing the synaptosomal fraction was similar in many respects to that used to isolate mitochondrial preparations of rat liver ${ }^{13,14}$. In an attempt to remove the contamination of mitochondria from nerve endings, the synaptosomal fraction of rat brain homogenates was subjected to separation in a discontinuous sucrose gradient by differential centrifugation or in a continuous Ficoll gradient by the rate zonal centrifugation technique ${ }^{15}$. Unfortunately, we found that the resulting fractions, which were enriched with nerve endings (as indicated by the activities of lactate dehydrogenase and acetycholinesterase), consumed oxygen poorly using substrates such as glucose or mitochondrial substrates (including malate, glutamate and succinate). This implied a loss of vesicular integrity of either the synaptosomes or the mitochondria. As a result, the purified preparation was unsuitable for use in the energy-requiring uptake assay, and so the synaptosomal preparation was chosen as the principal in vitro assay. However, as described in the main text, the experience of working with synaptosomal fractions eventually brought a new direction for central nervous system drug discovery research at Lilly.

elegant studies of $\left[{ }^{3} \mathrm{H}\right]-5$-HT-uptake kinetics in slices of the rat hypothalamus and striatum by Shaskan and Snyder ${ }^{43}$ attracted our attention. The investigators at the Johns Hopkins University showed that the uptake of $\left[{ }^{3} \mathrm{H}\right]-5-\mathrm{HT}$ at submicromolar concentrations depended on physiological conditions of temperature, glucose, sodium and time of incubation in an oxygenated Krebs-Henseleit-bicarbonate medium, and was inhibited by ouabain. Most importantly, they identified high- and low-affinity components of $\left[{ }^{3} \mathrm{H}\right]-5-\mathrm{HT}$ uptake with primary and secondary Michaelis-Menten constant $\left(K_{\mathrm{m} 1}\right.$ and $\left.K_{\mathrm{m} 2}\right)$ values of 0.14 and of $8 \mu \mathrm{M}$, respectively, in hypothalamic slices ${ }^{43}$. Earlier studies showed a single component of $\left[{ }^{14} \mathrm{C}\right]-5$-HT uptake in slices of the whole rat brain with intermediate $K_{\mathrm{m}}$ values of 0.57 and $0.7 \mu \mathrm{M}^{44,45}$. Consistent with the earlier findings of Carlsson and colleagues ${ }^{32,36}$, Shaskan and Snyder also reported that the tertiary-amine-containing TCAs clomipramine and imipramine were two orders of magnitude more potent inhibitors of the high-affinity $\left[{ }^{3} \mathrm{H}\right]-5-\mathrm{HT}$-uptake process in hypothalamic slices than the secondary amine-containing TCAs desipramine and nortriptyline ${ }^{43}$. Equally elegant studies of $\left[{ }^{3} \mathrm{H}\right]-\mathrm{NA}-$ and $\left[{ }^{3} \mathrm{H}\right]-\mathrm{DA}$-uptake kinetics were accomplished using homogenates of rat brain areas ${ }^{46}$.

We initially struggled when preparing slices from brain tissues. The lack of uniformity of $\left[{ }^{3} \mathrm{H}\right]-5-\mathrm{HT}$ and $\left[{ }^{3} \mathrm{H}\right]-\mathrm{NA}$ uptake in the slices made quantitative measurements and reproducibility difficult. The successful separation of the nerve endings containing fractions of rat brain homogenates (BOX 1) following centrifugation in either a discontinuous sucrose gradient or a continuous Ficoll gradient ${ }^{15}$ and the ease of preparation led us to quickly adopt the use of a synaptosomal fraction $\left(\mathrm{P}_{2}\right)$ of brain homogenates for the measurement of $\left[{ }^{3} \mathrm{H}\right]-5-\mathrm{HT}$ and $\left[{ }^{3} \mathrm{H}\right]-\mathrm{NA}$ uptake in vitro ${ }^{23}$. We were also encouraged by a study showing that exogenously introduced 5-HT in the medium was concentrated in nerve-ending fractions of a sucrose gradient containing homogenates that were prepared from slices of whole brain ${ }^{44}$. By the end of 1971, we had successfully differentiated the high- and the low-affinity components of $\left[{ }^{3} \mathrm{H}\right]-5$-HT uptake with $K_{\mathrm{m}}$ values of 0.10 and $7.9 \mu \mathrm{M}$, respectively, in synaptosomal preparations of the rat brain, in agreement with the $K_{\mathrm{m}}$ values that were found in brain slices ${ }^{43}$. In the same study, we also established inhibitor constant $\left(K_{\mathrm{i}}\right)$ values of 0.3 and 7 $\mu \mathrm{M}$ for $p$-chloroamphetamine ( $p$-CA) and amphetamine, respectively, for inhibition of the high-affinity $\left[{ }^{3} \mathrm{H}\right]-5$-HT-uptake process in nerve endings ${ }^{23}$. In the first week of January 1972, these findings were reported to members of the CNS Research Committee at Lilly. On the basis of these laboratory results, we proposed, a month later, that the processes of $\left[{ }^{3} \mathrm{H}\right]-5-\mathrm{HT}$ and $\left[{ }^{3} \mathrm{H}\right]-$ NA uptake in isolated nerve-ending preparations - as discussed in BOX 1 - would be biochemical targets in the search for monoamine-uptake inhibitors as potential antidepressive agents.

\section{The phenoxyphenylpropylamines (PPPAs)}

In 1970, Molloy (a medicinal chemist) and Rathbun (a pharmacologist) began their collaboration, which aimed to develop an agent that would retain the therapeutic activity of the TCAs, but which would be devoid of their undesirable effects on cardiac conduction as well as anticholinergic activity 9 . They used a test scheme that involved the reversal of apomorphine-induced hypothermia in mice - a test in which the TCAs were active as antagonists. Diphenhydramine (FIG. 2) was known to enhance the pressor response to NA, and was observed by Carlsson and colleagues at the University of Goteborg in Sweden to inhibit monoamine uptake in addition to antagonizing histamine receptors. The inhibition of monoamine uptake implied a potential usefulness in treating depression ${ }^{9}$. Molloy, along with colleagues Schmiegel and Hauser, synthesized many analogues of the antihistamine drug diphenhydramine. Kattau, in the Rathbun laboratory, then tested the newly synthesized molecules for their capacity to reverse apomorphine-induced hypothermia in mice. LY86032, which is a phenoxy analogue (FIG. 2), was highly effective in antagonizing apomorphine hypothermia in mice. Analysis of the structure-activity relationship (SAR) led to the identification of a molecule, DL-Nmethyl-3-(o-methoxyphenoxy)-3-phenylpropylamine $\mathrm{HCl}$ (later called nisoxetine hydrochloride; LY94939; FIG. 2), which was as effective as the TCAs in reversing the apomorphine-induced hypothermia.

Slater, who was the Director of the Pharmacological Research Division, requested the testing of LY94939 and three related molecules for their capacity to inhibit $\left[{ }^{3} \mathrm{H}\right]$-NA uptake in comparison with desipramine, as LY94939 seemed to have similar pharmacological 


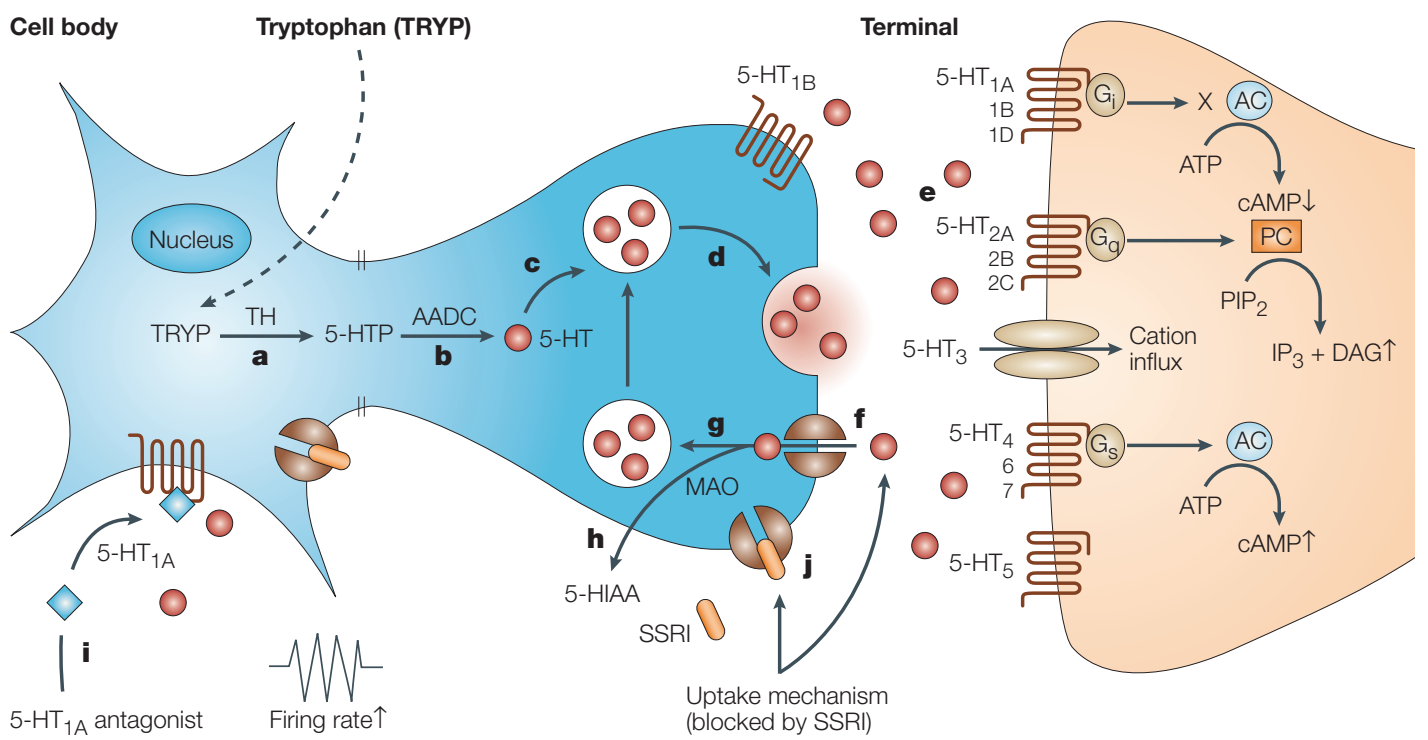

Figure 1 | Schematic of processes associated with serotonergic neurotransmission. a | Tryptophan hydroxylase (TH) catalyses the conversion of tryptophan (TRYP) to 5-hydroxytryptophan (5-HTP). b | Aromatic aminoacid decarboxylase (AADC) catalyses the conversion of 5-HTP to 5-hydroxytryptamine (5-HT, serotonin). c $\mid 5-\mathrm{HT}$ is taken up into storage vesicles. d | 5-HT is released from storage vesicles into the synaptic space. e | 5-HT can activate subtypes of 5-HT receptor families (1, 2, 3, 4, 5, 6 and 7), which couple with their respective system of signal transduction inside the postsynaptic neuron. $\mathbf{f} \mid 5-\mathrm{HT}$ is taken up into the presynaptic 5-HT terminals by the 5-HT transporter. g,h | Within the presynaptic 5-HT terminals, 5-HT would either be taken up by the storage vesicles or degraded by monoamine oxidase (MAO). i | 5-HT activates the presynaptic somatodendriatic 5- $\mathrm{HT}_{1 \mathrm{~A}}$ autoreceptor, which can be blocked by selective 5- $\mathrm{HT}_{1 \mathrm{~A}}$ antagonists. $\mathbf{j}$ | Selective serotonin-reuptake inhibitors (SSRIs) including fluoxetine inhibit the 5-HT transporter. 5-HIAA, 5 hydroxyindolacetic acid; AC, adenylate cyclase; DAG, diacylglycerol; $\mathrm{IP}_{3}$, inositol-1,4,5-trisphosphate; $\mathrm{PIP}_{2}$, phosphatidylinositol-4,5-bisphosphate.

properties to those of desipramine ${ }^{47}$. Indeed, LY94939 was as effective as desipramine at inhibiting $\left[{ }^{3} \mathrm{H}\right]-\mathrm{NA}$ uptake in the nerve endings of the rat hypothalamus, whereas both compounds were much less effective inhibitors of $\left[{ }^{3} \mathrm{H}\right]-5-\mathrm{HT}$ uptake ${ }^{24,25}$.

\section{Subtle differences in uptake inhibitors}

Pharmacological studies of the TCAs both in vivo ${ }^{22,34,35}$ and in vitro ${ }^{22,33,43}$ showed specificity for inhibiting monoamine-uptake processes, which can discern an extra methyl group in the tertiary-amine-containing TCAs from the secondary-amine-containing TCAs, as inhibitors of $\left[{ }^{3} \mathrm{H}\right]-5-\mathrm{HT}$ and $\left[{ }^{3} \mathrm{H}\right]-\mathrm{NA}$ uptake, respectively, in nerve-ending preparations. Compared with imipramine, clomipramine, which has one chloroatom added to one of the fused rings, was an order of magnitude more potent as an inhibitor of $\left[{ }^{3} \mathrm{H}\right]-5-\mathrm{HT}$ uptake $e^{22,32,43}$. Moreover, the introduction of a chloroatom to the para-position in the aromatic ring of amphetamine, as in $p$-CA, led to a more than tenfold increase in effectiveness at inhibiting $\left[{ }^{3} \mathrm{H}\right]-5-\mathrm{HT}$ uptake in nerve endings ${ }^{23}$. Having identified LY94939 as a selective NA-uptake inhibitor, we considered it highly likely that molecules with subtle chemical differences would be found among other analogues of LY94939 in the PPPA series, which might show selectivity as inhibitors of the two uptake processes.

In the course of studying the characteristics of 5-HT- and NA-uptake kinetics in vitro, and the search for selective inhibitors of 5-HT and NA uptake, we made considerable progress - but not without criticism. For example, an academic expert on 5-HT biochemistry and pharmacology, who acted as a consultant in CNS research, repeatedly discouraged the pursuit of selective inhibitors for monoamine uptake during his quarterly visits to Lilly. Other scientists offered the view that enhancing serotonergic neurotransmission might actually be depressogenic. However, owing to support from our immediate supervisor in the Physiological Research Division and, particularly, from Slater, who was an advisor to the CNS Research Committee, the project proceeded without interruption.

\section{Selective 5-HT uptake inhibitors in vitro}

The members of the series of PPPAs synthesized by Molloy and associates were among the first compounds to be tested. These compounds, as either primary or secondary amines, had substitutions on the aromatic phenoxy- or phenyl-rings, including the ortho-, meta- or para-positions, as well as substitutions on the propylamine side chain. The PPPAs were chosen irrespective of their ability to reverse the apomorphine-induced hypothermia that was observed in animal behavioural studies conducted by Kattau and Rathbun. These selected compounds were tested initially for their ability to inhibit the uptake of $\left[{ }^{3} \mathrm{H}\right]-5-\mathrm{HT}$ and $\left[{ }^{3} \mathrm{H}\right]-\mathrm{NA}$ in isolated synaptosomal preparations of the rat brain, thereby offering an appreciation of their SARs ${ }^{48}$. 
Among the selected analogues of LY94939, the compound LY82816 (3-p-trifluoromethyl-phenoxy$\mathrm{N}$-methyl-3-phenylpropylamine oxalate), which was a secondary amine (later named as fluoxetine oxalate), and its primary amine or $\mathrm{N}$-demethylated compound (later named as norfluoxetine; FIG. 2), were the most potent inhibitors of $\left[{ }^{3} \mathrm{H}\right]-5$-HT uptake in nerve endings, with $K_{\mathrm{i}}$ values of $0.07 \mu \mathrm{M}$. By contrast, fluoxetine and norfluoxetine were much weaker inhibitors of $\left[{ }^{3} \mathrm{H}\right]-\mathrm{NA}$ uptake, with $K_{\mathrm{i}}$ values of $8-10 \mu \mathrm{M}^{1,49,50}$. The $p$-trifluoromethyl substitution seemed to be optimal, as replacements with other substitutions (including $p$-OCH3, $p$ - $\mathrm{CH} 3, p-\mathrm{Cl}, p-\mathrm{F}$ and nonsubstituted compounds) were inferior and showed decreased effectiveness as inhibitors of 5-HT uptake. Moving the trifluoromethyl substitution from the para- to the meta- or orthoposition greatly reduced the effectiveness of the inhibition of 5-HT uptake, but increased the effectiveness of the inhibition of NA uptake $e^{50}$. The results obtained from the testing of these compounds in vitro were immediately disseminated. Although we continued the SAR studies of these compounds to assess their inhibitory effects on the uptake of 5-HT and NA in vitro, we concurrently developed a methodology to evaluate the effects of LY82816 (the oxalate salt) and subsequently LY110140 (the $\mathrm{HCl}$ salt) - this compound, irrespective of the salt form, is referred to as fluoxetine hereafter - on the uptake of $\left[{ }^{3} \mathrm{H}\right]-5-\mathrm{HT}$ and $\left[{ }^{3} \mathrm{H}\right]-\mathrm{NA}$ in vivo.

\section{Selective inhibition of 5-HT uptake in vivo}

The available animal models of depression during this period were developed using the TCAs and were biased towards noradrenergic drugs. Fluoxetine did not have marked activity in these models and it was therefore crucial to establish the inhibition of 5-HT uptake in vivo. We explored several approaches to assess the effectiveness and selectivity of fluoxetine and norfluoxetine as inhibitors of 5-HT uptake in vivo. Using the method that had previously been developed to examine the effects of drugs ex vivo ${ }^{15,23}$, fluoxetine and clomipramine were compared and found to inhibit $\left[{ }^{3} \mathrm{H}\right]-5-\mathrm{HT}$ uptake in nerve endings with similar effectiveness ${ }^{1,49}$. The uptake of $\left[{ }^{3} \mathrm{H}\right]-5$-HT in nerve endings prepared from the brains of drug-treated rats was significantly reduced, by 56 and $24 \%$, after treatment with $10 \mathrm{mg}$ per $\mathrm{kg}$ intraperitoneal doses of fluoxetine and clomipramine, respectively. The inhibitory effect of fluoxetine lasted for up to $24 \mathrm{~h}$ after a single administration, whereas that of clomipramine peaked after $1 \mathrm{~h}$ and disappeared after $4 \mathrm{~h}^{1,50}$. Moreover, fluoxetine was most effective at inhibiting $\left[{ }^{3} \mathrm{H}\right]-5-\mathrm{HT}$ uptake in synaptosomal preparations that were isolated from the cerebral cortex and brain stem areas, and had no effect on the activity of tryptophan hydroxylase in the five rat brain regions that were examined. Treatment with either fluoxetine or clomipramine did not change the uptake of $\left[{ }^{3} \mathrm{H}\right]$-NA and $\left[{ }^{3} \mathrm{H}\right]$-DA in these preparations of nerve endings during the time-course study. The indirect assessment of drug effects ex vivo pointed to the effectiveness and selectivity of fluoxetine for inhibiting the uptake of $\left[{ }^{3} \mathrm{H}\right]-5-\mathrm{HT}$ versus that of $\left[{ }^{3} \mathrm{H}\right]-\mathrm{NA}$.
An alternative method, which measured the accumulation of radioactivity in the heart following the intravenous injection of radioactive NA, according to the method of Hertting and colleagues ${ }^{31}$, was a more direct assessment of the effects on the uptake of NA in vivo. The accumulation of radioactivity in rat hearts following an intravenous injection of radioactive NA was dose-dependently decreased by pretreatment with TCAs, including desipramine, imipramine, desmethylclomipramine and clomipramine (in order of decreasing effectiveness). However, neither fluoxetine nor its main desmethylated metabolite, norfluoxetine, inhibited the uptake of NA into rat hearts ${ }^{1,50}$. Therefore, this direct assessment of the accumulation of radioactivity following the administration of radioactive NA confirmed that fluoxetine at doses that inhibited 5-HT uptake ex vivo did not inhibit the peripheral uptake of NA in vivo.

Fluoxetine was also found to be a potent inhibitor of the saturable $\left[{ }^{3} \mathrm{H}\right]-5$-HT-uptake process in blood platelets from rats and humans with half-maximal inhibitory concentration $\left(\mathrm{IC}_{50}\right)$ values of 0.10 and 0.05 $\mu \mathrm{M}$, respectively ${ }^{51,52}$. Pretreatment with fluoxetine and clomipramine significantly lowered the accumulation of $\left[{ }^{3} \mathrm{H}\right]$-radioactivity in rat platelets (by $63 \%$ and $53 \%$, respectively) from an intravenously administered dose of $\left[{ }^{3} \mathrm{H}\right]-5-\mathrm{HT}$, whereas pretreatment with desipramine had no significant effects. So, fluoxetine was again shown to be a potent and selective inhibitor of peripheral 5-HT uptake in vivo.

To confirm that fluoxetine inhibited 5-HT, but not NA, uptake into their respective neurons in the brain, its ability to prevent the effects of the uptakedependent and neuron-specific toxins was examined, as shown with the TCAs by Carlsson and collaborators $^{34,35}$, and with fluoxetine by Fuller and associates ${ }^{2,53}$. Consistent with the prevention of the depletion of 5 -HT in the brain elicited by $p-\mathrm{CA}^{2,53}$, fluoxetine effectively blocked the loss of $\left[{ }^{3} \mathrm{H}\right]-5-\mathrm{HT}$ uptake in cortical homogenates of the $p$-CA-treated rats with a half-maximal effective dose $\left(\mathrm{ED}_{50}\right)$ value of $3.8 \mathrm{mg}$ per $\mathrm{kg}$ intraperitoneally. Fluoxetine at intraperitoneal doses of up to $50 \mathrm{mg}$ per kg did not prevent the 6-hydroxydopamine (6-OHDA)-induced loss of $\left[{ }^{3} \mathrm{H}\right]$-NA in hypothalamic homogenates ${ }^{54}$, which was consistent with its inability to prevent the 6-OHDA-induced depletion of NA in rat hearts ${ }^{2,53}$. Indeed, fluoxetine was confirmed as a selective inhibitor of 5-HT uptake in the rat brain in vivo.

\section{In vivo pharmacology of fluoxetine}

Inhibition of 5-HT uptake in vivo. Fuller had a longtime interest in drugs that affected brain monoamines before the arrival of fluoxetine in his laboratory in 1972. In particular, Fuller and his collaborators had studied the effects of various halogenated amphetamine derivatives as inhibitors of $\mathrm{MAO}^{55,56}$. He also had a special interest in studying the depletion of rat brain $5-\mathrm{HT}$ by $p-\mathrm{CA}^{57-59}$. Interestingly, this effect of $p$-CA was subsequently shown to be blocked in vivo by drugs that inhibited the 5-HT-uptake processes ${ }^{60,61}$. The scientists 


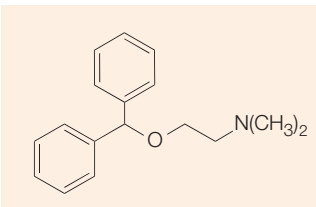

Diphenhydramine

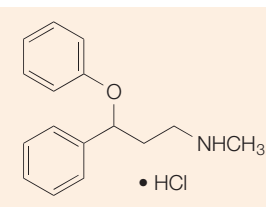

LY86032

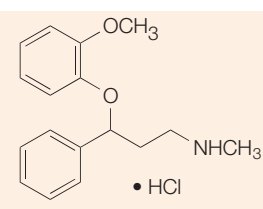

Nisoxetine (LY94939)

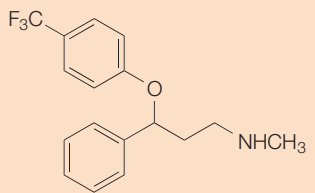

Fluoxetine

(oxalate salt, LY82816:

hydrochloride salt, LY110140
Figure 2 | Structures of diphenhydramine, LY86032, nisoxetine, fluoxetine and norfluoxetine. way to do this was by measuring the concentrations of the 5-HT metabolite 5-HIAA in the brain. Previous results obtained with the older generation of antidepressants (the TCAs) had shown that some, such as imipramine, could decrease the 5-HIAA concentrations ${ }^{63}$. Initially, we obtained erratic results with the original fluorescence assay for 5-HIAA ${ }^{64}$. On investigation, we realized that this problem was caused by its chemical instability under highly acidic conditions. We found that the addition of the antioxidant cysteine could stabilize 5-HIAA. Once this problem was solved, we were rapidly able to show that fluoxetine decreased the concentration of 5-HIAA in the rat brain by $\sim 20 \%$. We then used two different methods to assess the effects of fluoxetine on 5-HT turnover: the accumulation of 5-HT after MAO inhibition and the accumulation of 5-HIAA after probenecid administration. Both methods showed a reduction of 5-HT turnover after fluoxetine administration ${ }^{2}$.

Consistent with the decreased turnover of 5-HT, as indicated by the decrease in the main metabolite, 5 -HIAA, on treatment with fluoxetine in vivo ${ }^{2,65}$, fluoxetine treatment at doses that were known to inhibit 5-HT uptake dose-dependently decreased the conversion of $\left[{ }^{3} \mathrm{H}\right]$-tryptophan into $\left[{ }^{3} \mathrm{H}\right]-5-\mathrm{HT}$ and $\left[{ }^{3} \mathrm{H}\right]-5$-HIAA in the rat brain ${ }^{5,66}$. The decreased conversion of $\left[{ }^{3} \mathrm{H}\right]$-tryptophan to $\left[{ }^{3} \mathrm{H}\right]-5-\mathrm{HT}$ and $\left[{ }^{3} \mathrm{H}\right]-$ 5-HIAA, and the decrease in 5-HIAA content, were most pronounced in the rat cerebral cortex and brain stem. Fluoxetine administration in vivo had no effect on the accumulation of $\left[{ }^{3} \mathrm{H}\right]$-tryptophan in the brain or on the activity of tryptophan hydroxylase in synaptosomal preparations. We interpreted these findings ${ }^{66}$ as an indication of a decrease in 5-HT synthesis resulting from a reduction in the firing of 5-HT neurons after 5-HT-uptake inhibition by fluoxetine in $v i v o^{67}$.

As fluoxetine was not a potent inhibitor of tryptophan hydroxylase in vitro, we believed that the reduction in 5-HT turnover that was caused by fluoxetine was due to increased 5-HT in the synapse, which led to the stimulation of receptors that were responsible for the control of 5-HT synthesis, as had been shown for chlorimipramine ${ }^{61}$. However, there was no direct way to show that fluoxetine increased the extracellular concentrations of 5-HT at the time. Later work that used the microdialysis technique confirmed that this was the correct interpretation ${ }^{68}$.

Postsynaptic effects of fluoxetine. The effects of fluoxetine on 5-HT synthesis and metabolism discussed above were attributed to the influence of increased extracellular 5-HT on presynaptic autoreceptors. However, an effect on postsynaptic receptors was also noted relatively early in the development of fluoxetine by Fuller and his assistant Snoddy ${ }^{69}$. They reported an elevation of plasma corticosterone that was transitory with fluoxetine alone, but which was more robust and longer lasting when fluoxetine was combined with L-5-hydroxytryptophan, which is a 5-HT precursor. The augmentation that resulted from combining $\mathrm{L}-5$ hydroxytryptophan and fluoxetine was an indication 
of enhanced serotonergic neurotransmission, which, in turn, elicited adrenocorticotropic hormone (ACTH) release and caused an elevation of corticosterone levels. It was also found that fluoxetine and L-5-hydroxytryptophan increased the release of prolactin, which was another postsynaptic effect that resulted from increased serotonergic transmission ${ }^{67}$.

\section{Reports on the discovery of fluoxetine}

We first disclosed our pharmacological studies of fluoxetine in a series of oral presentations at the 1974 annual meetings of the Federation of American Societies for Experimental Biology and the American Society of Pharmacology and Experimental Therapeutics ${ }^{49,51,53,55,70}$. These findings were also published in the same year ${ }^{1,2,62}$. In the initial publications on fluoxetine, which were based on the relevant pharmacological results and clinical observations s, $^{29,35}$ (as mentioned above), we proposed that fluoxetine would be a potential antidepressant drug in addition to being a valuable tool to explore the roles of 5-HT neurons in various physiological and endocrinological processes ${ }^{1,71}$. Because of the inability of fluoxetine to produce overt behaviours or the TCA-like behavioural effects that were known to pharmacologists at the time, we encountered criticism as well as scepticism from a few colleagues, who did not think that a molecule that selectively inhibited 5-HT uptake could become an antidepressant drug. As mentioned above, fluoxetine did not have marked activity in the available animal models of depression, such as the forced swim test and apomorphine-induced hypothermia, which raised further questions about the antidepressant potential of the compound. However, we were much encouraged by a timely publication by Asberg and colleagues ${ }^{72}$, who suggested that a subgroup of patients with endogenous depression were deficient in serotonergic function and would be helped more by a drug that acted selectively on 5-HT than by the drugs that were available at the time.

\section{Fluoxetine in development}

In 1973, we presented the laboratory findings concerning fluoxetine to the CNS Research Committee at Lilly, which, following our presentation, recommended the formation of a project team on fluoxetine to guide it to product development (TIMELINE). With the leadership of Fuller as chair/secretary of the CNS Research Committee and Slater, who was a member of research management and provided support behind the scenes, the project team, which was known as Psychotropic Agent LY110140 (referred to as 'the team' hereafter), was formed that year. Fuller served as chairperson, and Molloy and Wong were members. This was the beginning of many years of effort by several key people to keep the project alive and to work towards a successful New Drug Application (NDA) submission to the US FDA, which finally occurred, after some delays, in 1983.

Shortly after the formation of the team, a sufficient quantity of fluoxetine was made available for toxicological evaluation in rats and dogs. The team learned that tissues that had been obtained from the necropsy of animals treated with daily doses of fluoxetine showed the presence of PHOSPHOLIPIDOSIs; therefore, they quickly put the safety studies on hold and searched for an explanation. After almost 9 months of pondering, the team made a consulting visit to the Neuropharmacology Division at the US FDA and learned that cationic amphiphilic molecules could cause the reversible accumulation of phospholipids in tissues. Several marketed drugs were known to cause phospholipidosis in animals and no problematic side effect had been found in humans, so the team recommended the resumption of safety studies of fluoxetine. By 1976, the safety studies in animals were completed and an Investigational New Drug (IND) application was filed with the US FDA (TIMELINE).

In 1976, Lemberger, who was a clinical investigator at the Lilly Laboratory for Clinical Research, first administered fluoxetine to humans ${ }^{9}$. Lemberger and colleagues found that doses of fluoxetine as high as $90 \mathrm{mg}$ were well tolerated by volunteers. As seen in rats ${ }^{52}$, the uptake of $\left[{ }^{3} \mathrm{H}\right]-5-\mathrm{HT}$ by blood platelets taken from fluoxetine-treated human volunteers was inhibited ${ }^{73,74}$ and the content of 5-HT in the blood platelets decreased following repeated doses $^{74}$. Lemberger and colleagues also showed that fluoxetine failed to potentiate the pressor response to intravenously administered NA in volunteers or to antagonize the pressor response to tyramine $e^{73,74}$. It was a truly rewarding experience to find, for the first time in humans, that fluoxetine selectively and effectively inhibited 5-HT uptake by blood platelets and had no demonstrable adrenergic effects on the cardiovascular system, even though both processes were in peripheral systems.

With the successful completion of the Phase I clinical safety studies, fluoxetine was ready to advance to Phase II, which involved searching for indications of effectiveness in treating depressed patients. However, the company had other drug candidates with higher priorities and lacked an experienced clinical investigator in psychiatry; consequently, the Phase II trials of fluoxetine in depressed patients almost came to a halt. Owing to limited resources, the initial clinical trial was a relatively small-scale study of fluoxetine in depressed patients and the drug was found to be ineffective. This was a great disappointment to those who were intimately involved with the project. We were subsequently informed that the unsuccessful trial was probably due to the type of patients who were involved, because they had previously been found to be refractory to other antidepressive treatments. Therefore, the team resolved to continue the development of fluoxetine and to repeat the study in a group of depressed patients who were less difficult to treat.

After a long search, a young psychiatrist was finally hired for the role of clinical investigator for fluoxetine. For almost 2 years, he searched for suitable centres in the United States in which to conduct the clinical trials on fluoxetine. However, before initiating the studies, he found a position elsewhere and left Lilly for his 


\section{Timeline | Key milestones in the development of fluoxetine (Prozac)}

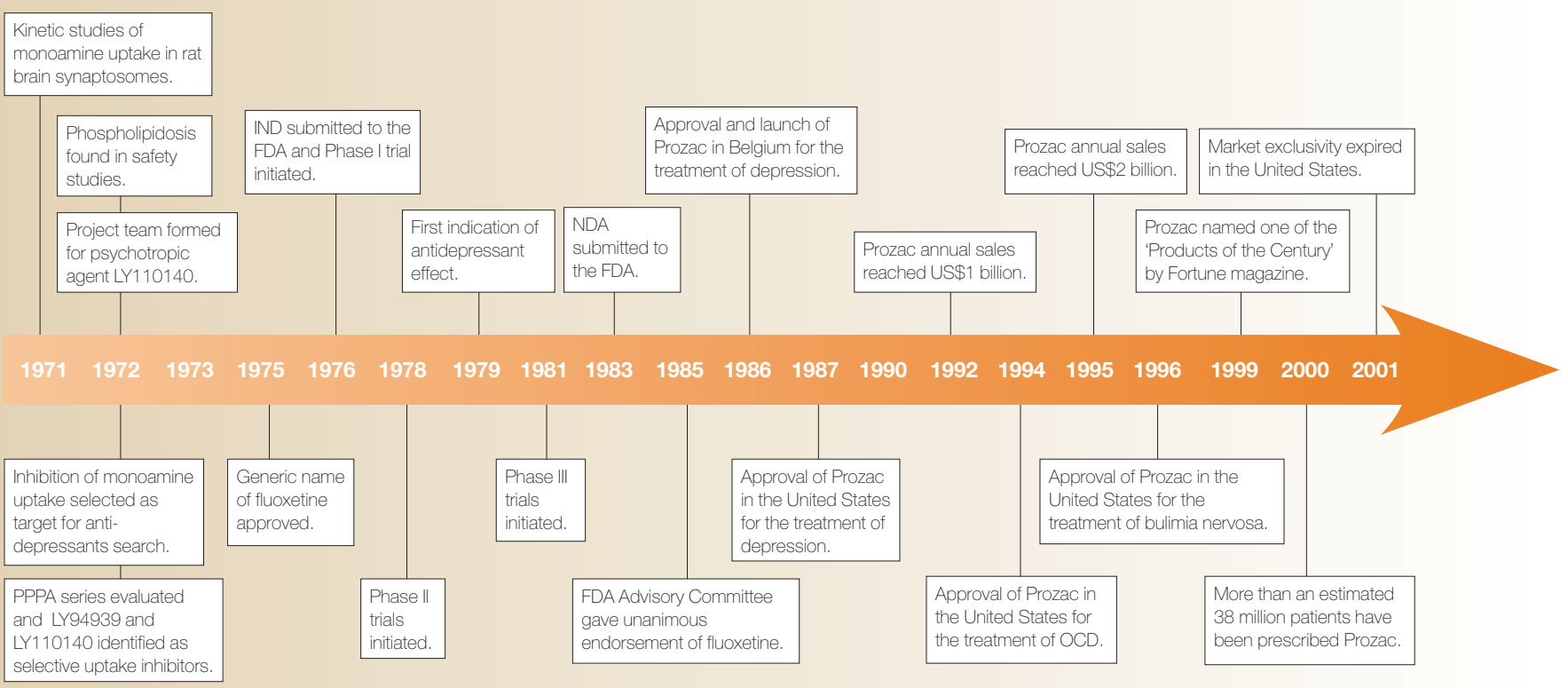

FDA, Food and Drug Administration; IND, Investigational New Drug application; NDA, New Drug Application; OCD, obsessive-compulsive disorder; PPPA, phenoxyphenylpropylamines.

own medical practice. Consequently, Slater, who was a well-recognized pharmacologist and also a physician experienced in directing clinical research, was asked to coordinate the clinical trials of fluoxetine. Encouraging results from open-label studies in depressed patients were eventually seen just before his retirement. Stark, who was a pharmacologist, took over the responsibility for the Phase III clinical trials of fluoxetine, and expeditiously brought the trials to a definitive and successful conclusion ${ }^{9}$. Fluoxetine was shown to be effective in the treatment of major depression. Consistent with its weak affinity for muscarinic acetylcholinergic, $\alpha$-adrenergic and histaminergic receptors, as well as the receptors of most neurotransmitters ${ }^{75}$, fluoxetine had fewer side effects than the TCAs, including low levels of dry mouth, blurred vision, constipation, postural hypotension, drowsiness and sedation. Most importantly, fluoxetine was devoid of the direct effect on the electrical conductivity of the heart that is seen with high doses of the TCA class of drugs ${ }^{76-78}$. The clinical results of the fluoxetine trials were compiled in more than 100 volumes of 2-inch binders for the submission of an NDA to the US FDA in 1983. It had taken more than 7 years from the day of the first human dose to the day of submission of the NDA (TIMELIME).

In the meantime, Astra Pharmaceuticals, with help from the Carlsson group, had introduced the SSRI zimelidine (Zelmid) in Europe in 1982 for the treatment of depression. We thought that we had lost the opportunity to be the first to market, but zimelidine was not on the market for long, because it was soon discovered to induce some rare but undesirable side effects, one of which was an influenza-like syndrome ${ }^{79}$. Surprisingly, we also learned that Astra
Pharmaceuticals had decided to terminate all research concerning SSRIs. So, we were once again hopeful that fluoxetine would be the first drug of its class to be widely available for the many depressed patients who were in need of a safer treatment and were, indeed, fortunate that the Lilly clinical team was so persistent.

About 2 years after the submission of the NDA for fluoxetine, the FDA Advisory Committee met, in October 1985, to consider its merits for approval. Although a query was raised about the potential of fluoxetine to produce an influenza-like response similar to that found with zimelidine, members of the advisory committee were satisfied with the explanation that this particular side effect was probably specific to zimelidine, which had a molecular structure that was markedly different from that of fluoxetine. Shortly afterwards, members of the committee stated that they considered fluoxetine to be safe and effective, and gave a unanimous recommendation for its approval for the treatment of depression. The team returned to Indianapolis in high spirits.

We anxiously waited for the final approval from the FDA, but this did not come until 2 years and 2 months later. Lilly Research Laboratories, which is a Division of Eli Lilly and Company, customarily closed its operations during the week between Christmas Day and New Year's Day. Therefore, we received the news of the FDA approval of fluoxetine for marketing as an antidepressant drug through watching the local television news on 29 December 1987. To many of us, the news brought not only excitement, but also an ultimate vindication, as we had carried the burden of the project, and had been ridiculed for many years as the ones who discovered and developed a molecule 
looking for a disease. From the first kinetic studies that differentiated 5-HT uptake from NA uptake in the nerve endings of the rat brain, and the first study showing that fluoxetine was an effective and selective inhibitor of 5-HT uptake in vitro, the journey of fluoxetine took more than 16 years. It also required a great deal of resources, energy and dedication from hundreds of individuals inside and outside of Lilly, as well as the participation of thousands of patients in clinical trials, to make it a reality (TIMELINE). In January 1988, fluoxetine was launched under the trade name Prozac. In retrospect, its introduction might have occurred substantially sooner, if we had known the importance and reversibility of phospholipidosis in drug-treated animals, and if a competent clinical investigator in psychiatry had been available during earlier stages of the project.

\section{The impact of fluoxetine}

Clarifying the role of 5-HT. Fluoxetine has been widely used as a tool for dissecting the role of 5-HT in CNS physiology and pathophysiology. Shortly after the 1974 publication of the characterization of the selective pharmacology of fluoxetine, samples were made available to outside investigators. At this time, there were no selective drugs for the 5-HT systems, so fluoxetine, with its high selectivity for such systems, was important in clarifying the pharmacology of 5-HT in animals and humans $s^{5}$. For example, PubMed lists $\sim 6,000$ papers that have been published on fluoxetine, which indicates the widespread use of the drug to explore the role of 5 -HT in brain function. The first two papers from the Wong laboratory that characterized the pharmacology of fluoxetine have been cited more than 760 times in the scientific literature.

Effect on the treatment of depression. Recent studies have found a widespread incidence of depression, and it has been estimated that up to $24 \%$ of women and $15 \%$ of men will suffer from this disorder during their lifetimes ${ }^{80}$. Depression has been ranked fourth in the order of worldwide disease burden and it is estimated that it will rise to second place by 2020 (REF. 81). It should also be remembered that depression is a principal cause of suicide, which is, in turn, among the main causes of death ${ }^{82}$. There is therefore a considerable need for effective treatments for this disorder.

The introduction of fluoxetine, which was the first SSRI to be marketed in the United States, has arguably had a pronounced effect on the treatment of depression, on depressed patients and on the perception of mental illness; its introduction has been said to have ushered in a new era of safe and effective pharmacotherapy for depression ${ }^{83}$. The sustained effectiveness of fluoxetine, low side-effect profile, overdose safety, once-a-day dosing, lack of a requirement for dose titration and improved risk-benefit ratio have led to widespread use by physicians ${ }^{84}$. It is estimated by Eli Lilly and Company that by the year 2002, more than 40 million patients had received fluoxetine, and many millions more have been treated with other successful SSRIs, including sertraline (Zoloft; Pfizer), which became the second SSRI to be introduced in the United States in 1992, paroxetine (Paxil; GlaxoSmithKline) and citalopram (Celexa; Forest Pharmaceuticals). Numerous lives have been saved from suicide by the widespread use of these drugs, as well as many relationships restored and careers saved.

Psychiatrists have described the discovery of fluoxetine as a giant step forward in the pharmacotherapy of depression ${ }^{84}$. This is now a highly treatable disease with response rates of $60-70 \%$ owing to the use of antidepressants ${ }^{85,86}$. However, noncompliance resulting from several factors, including side effects and challenging dosing schedules with TCAs, is an important issue with this class of drugs. Although they were not as severe as the adverse event profiles of the TCAs, fluoxetine and the other SSRIs were found to have treatment-emergent adverse events, including insomnia, anxiety, nausea and vomiting, and sexual dysfunction $^{87}$. Also, potential drug-drug interactions were identified owing to the inhibition of CYP4502D6 enzymes by fluoxetine ${ }^{88}$.

Nevertheless, overall, the ease of use, safety and relatively benign side effects of fluoxetine have led to better patient acceptance, compliance and outcomes $^{84}$. Effective treatment of depression with fluoxetine and other SSRIs not only reduces the suffering and disability of patients, but decreases the cost of healthcare owing to the reoccurrence of depres$\operatorname{sion}^{8,83}$. Psychiatrists now have a safe, effective and well-tolerated armamentarium in fluoxetine and other SSRIs for the treatment of this severe mental illness. Furthermore, the success of fluoxetine has heightened awareness of depression, underscored the crucial need for treatment and reduced the stigma associated with the disorder. Having an underlying biological rationale for a treatment - that is, the modulation of serotonergic function - also helped to improve the public understanding of the role of mental-health professionals, as it provided a clear basis for discussing the biology of a psychiatric disorder. Finally, the use of fluoxetine and the other SSRIs has expanded beyond depression and they are effectively used, often as a first choice, in anorexia nervosa, bulimia nervosa, obsessive-compulsive disorder, panic disorder, premenstrual dysphoria and generalized anxiety disorder. Indeed, this is not surprising, owing to the manifold effects of 5-HT in the brain.

It was only a few years after the discovery of the presence of 5-HT in the brain that Page and McCubbin (1956) suggested that "serotonin has provided tenure for pharmacologists whose livelihood was becoming threadbare due to exhaustive study of other biogenic amines such as catecholamine and histamine" ${ }^{\prime 29}$. Certainly the same can be said for fluoxetine, which came along $\sim 20$ years later. It has been the subject of intensive study not only by pharmacologists but also by countless other researchers in the mental healthcare field and will probably continue to be studied for many years to come. 


\section{Concluding thoughts}

As we look back more than 30 years to the discovery of fluoxetine, several key thoughts come to mind. Scientific knowledge is a continuous building process, and we are indebted to the pioneering scientists during the embryonic years of neuroscience research who first highlighted the importance of 5-HT and NA in the brain. Our Swedish colleagues proposed the seminal hypothesis that 5-HT neurotransmission could be enhanced by decreasing 5-HT clearance through uptake inhibition. Our experience with the discovery of fluoxetine shows that new ideas that are not in the mainstream of scientific thought are often greeted with scepticism and even derision. We encourage scientists to carefully and thoughtfully develop hypotheses, and then proceed to thoroughly test them in spite of criticism from colleagues. As shown by this case history, it takes many dedicated and talented people to develop a drug, and we express our sincere gratitude to all those who assisted fluoxetine in its long journey. Finally, as clearly illustrated by the discovery of fluoxetine, it is essential that ideas are steadfastly championed by passionate believers to achieve the final goal.
1. Wong, D. T., Horng, J. S., Bymaster, F. P., Hauser, K. L. \& Molloy, B. B. A selective inhibitor of serotonin uptake: Lilly 110140, 3-(p-trifluoromethylphenoxy)- $N$-methyl-3phenylpropylamine. Life Sci. 15, 471-479 (1974). This was the first report to describe the discovery, and give a brief characterization, of fluoxetine (LY110140) as a selective inhibitor of 5-HT uptake. The authors considered the possibility that fluoxetine would be an antidepressant drug and a useful research tool.

2. Fuller, R. W., Perry, K. W. \& Molloy, B. B. Effect of an uptake inhibitor on serotonin metabolism in rat brain: studies with 3-( $p$-trifluoromethylphenoxy)- $N$-methyl-3phenylpropylamine (Lilly 110140). Life Sci. 15, 1161-1171 (1974).

This was the first published study to show the effect of fluoxetine on the metabolism of 5-HT in the rat brain.

3. Fuller, R. W. \& Wong, D. T. Inhibition of serotonin uptake. Fed. Proc. Fed. Am. Soc. Exp. Biol. 36, 2154-2158 (1977).

4. Fuller, R. W., Wong, D. T. \& Robertson, D. W. Fluoxetine, a selective inhibitor of serotonin uptake. Med. Res. Rev. 11, 17-34 (1991).

5. Wong, D. T., Bymaster, F. P. \& Engleman, E. A. Prozac (fluoxetine, Lilly 110140), the first selective serotonin uptake inhibitor and an antidepressant drug (in US): twenty years since its first publication. Life Sci. 57, 411-441 (1995).

This review provided the rationale for searching a selective inhibitor of 5-HT uptake and described the comprehensive preclinical pharmacology of fluoxetine.

6. Stark, P. \& Hardison, C. D. A review of multicenter controlled studies of fluoxetine vs imipramine and placebo in outpatients with major depressive disorder. J. Clin. Psychiatry 46, 53-58 (1985).

This publication reviewed the early clinical studies that established fluoxetine as an efficacious antidepressant drug.

7. Boyer, W. F. \& Feighner, J. P. in Perspectives in Psychiatry, Volume 1: Selective Serotonin Re-uptake Inhibitors (eds Feighner, J. P. \& Boyer, W. F.) 89-108 (Wiley, Chichester, England, 1991).

8. Stokes, P. Fluoxetine: a five-year review. Clin. Ther. 15, 216-243 (1993)

9. Molloy, B. B., Wong, D. T. \& Fuller, R. W. The discovery of fluoxetine. Pharmaceutical News 1, 6-10 (1994).

10. Bourne, G. H. The Structure and Function of Nervous Tissue, III: Biochemistry and Disease (Academic Press, New York, 1969).

11. Gray, E. G. \& Whittaker, V. P. The isolation of nerve endings from brain: an electron-microscopic study of cell fragments derived by homogenization and centrifugation. J. Anat. $\mathbf{9 6}$ 79-88 (1962).

12. Whittaker, V. P. in The Structure and Function of Nervous Tissue, III: Biochemistry and Disease (ed. Bourne, G. H.) 1-24 (Academic Press, New York, 1969).

13. Wong, D. T., Horng, J. S., Hamill, R. L. \& Lardy, H. A Effect of a new monocarboxylic acid antibiotic, A204, on the monovalent cation permeability of rat liver mitochondria. Biochem. Pharmacol. 20, 3169-3177 (1971).

14. Wong, D. T., Wilkinson, J. R., Hamill, R. L. \& Horng, J. S. Effects of antibiotic ionophore, A23187, on oxidative phosphorylation and calcium transport of liver mitochondria. Arch. Biochem. Biophys. 156 578-585 (1973).
15. Wong, D. T., Van Frank, R. M., Horng, J. S. \& Fuller, R. W. Accumulation of amphetamine and $p$-chloroamphetamine into synaptosomes of rat brain. J. Pharm. Pharmacol. 24 171-173 (1972).

16. Page, I. in Serotonin and the Brain (ed. Bourne, G. H.) 289-307 (Academic Press, New York, 1969).

17. Rapport, M. M., Green, A. A. \& Page, I. H. Crystalline serotonin. Science 108, 329-330 (1948).

18. Twarog, B. M. \& Page, I. H. Serotonin content of some mammalian tissues and urine and a method for its determination. Am. J. Physiol. 175, 157-161 (1953).

19. Weil-Malherbe, H. \& Szara, S. I. in The Biochemistry of Functional and Experimental Psychoses 5-16 (Thomas, Springfield, Illinois, 1971).

20. Dahlstrom, A. \& Fuxe, K. Evidence for the existence of monoamine containing neurons in the central nervous system. I. Demonstration of monoamines in the cell bodies of brain stem neurons. Acta Physiol. Scand. 62 (Suppl. 232), 1-55 (1964)

21. Fuxe, K., Hokfelt, T. \& Ungerstedt, U. Localization of indolalkylamines in CNS. Adv. Pharmacol. 6A, 235-251 (1968).

22. Lindbrink, P., Jonsson, G. \& Fuxe, K. The effect of imipramine-like drugs and antihistamine drugs on uptake mechanisms in the central noradrenaline and 5-hydroxytryptamine neurons. Neuropharmacology 10, 521-536 (1971).

23. Wong, D. T., Horng, J. S. \& Fuller, R. W. Kinetics of serotonin accumulation into synaptosomes of rat braineffects of amphetamine and chloroamphetamines. Biochem. Pharmacol. 22, 311-322 (1973).

24. Wong, D. T., Horng, J. S. \& Bymaster, F. P. DL-N-methyl-3(o-methoxyphenoxy)-3-phenylpropylamine hydrochloride, Lilly 94939, a potent inhibitor for uptake of norepinephrine into rat brain synaptosomes and heart. Life Sci. 17, 755-760 (1975).

25. Wong, D. T. \& Bymaster, F. P. Effect of nisoxetine on uptake of catecholamines in synaptosomes isolated from discrete regions of rat brain. Biochem. Pharmacol. 25, 1979-1983 (1976).

26. Bunney, W. E. Jr. \& Davis, J. M. Norepinephrine in depressive reactions. A review. Arch. Gen. Psychiatry 13, 483-494 (1965).

27. Schildkraut, J. J. The catecholamine hypothesis of affective disorders: a review of supporting evidence. Am. J. Psychiatry 122, 509 -522 (1965).

28. Axelrod, J. Noradrenaline: fate and control of its biosynthesis. Science 173, 598-606 (1971).

29. Weil-Malherbe, H. \& Szara, S. I. in The Biochemistry of Functional and Experimental Psychoses 57-76 (Thomas, Springfield, Illinois, 1971)

30. Gillette, J. R., Dingell, J. V., Sulser, F., Kuntzman, R. \& Brodie, B. B. Isolation from rat brain of a metabolic product, desmethylimipramine, that mediates the antidepressant activity of imipramine (Tofranil). Experientia (Basel) 17, 417-418 (1961)

31. Hertting, G., Axelrod, J. \& Whitby, L. G., Effect of drugs on the uptake and metabolism of $3 \mathrm{H}$-norepinephrine. J. Pharmacol. Exp. Ther. 134, 146-153 (1961).

32. Carlsson, A. Structural specificity for inhibition of [3H]-5hydroxytryptamine uptake by cerebral slices. J. Pharm. Pharmac. 22, 729-732 (1970)

33. Carlsson, A., Fuxe, K. \& Ungerstedt, U. The effect of imipramine on central 5-hydroxytryptamine neurons. J. Pharm. Pharmacol. 20, 150-151 (1968).

34. Carlsson, A., Corrodi, H., Fuxe, K. \& Hokfelt, T. Effects of some antidepressant drugs on the depletion of intraneuronal brain catecholamine stores caused by $4, \alpha$-dimethyl-metatyramine. Eur. J. Pharmacol. 5, 367-373 (1969).
35. Carlsson, A., Corrodi, H., Fuxe, K. \& Hokfelt, T. Effect of antidepressant drugs on the depletion of intraneuronal brain 5-hydroxytryptamine stores caused by 4 -methyl- $\alpha$ ethyl-meta-tyramine. Eur. J. Pharmacol. 5, 357-366 (1969).

36. Carlsson, A., Fuxe, K., Hamberger, B. \& Lindqvist, M. Biochemical and histochemical studies on the effects of imipramine-like drugs and (+)-amphetamine on central and peripheral catecholamine neurons. Acta Physiol. Scand. 67, 481-497 (1966).

37. Shaw, D. M., Camps, F. E. \& Eccleston, E. G. 5hydroxytryptamine in the hind-brain of depressive suicides. Br. J. Psychiatry 113, 1407-1411 (1967).

38. Bourne, H. R. et al. Noradrenaline, 5-hydroxytryptamine and 5-hydroxyindoleacetic acid in hindbrains of suicida patients. Lancet 2, 805-808 (1968).

39. Pare, C. M., Yeung, D. P., Price, K. \& Stacey, R. S. 5-hydroxytryptamine, noradrenaline and dopamine in brain stem, hypothalamus and caudate nucleus of control and of patients committing suicide by coal-gas poisoning. Lancet 2, 133-135 (1969).

40. Coppen, A., Shaw, D. M. \& Farrell, J. P. Potentiation of the antidepressive effect of a monoamine oxidase inhibitor by tryptophan. Lancet 1, 79-81 (1963).

41. Pare, C. M. B. Potentiation of monoamine oxidase inhibitors by tryptophan. Lancet // 35, 527-528 (1963).

42. Kline, N. S. \& Sack, W. Relief of depression within one day using an M. A. O. inhibitor and intravenous 5-HTP. Am. J. Psychiatry 120, 274-275 (1963).

43. Shaskan, E. G. \& Snyder, S. H. Kinetics of serotonin accumulation into slices from rat brain: relationship to catecholamine uptake. J. Pharm. Exp. Ther. 175, 404-418 (1970).

44. Blackburn, K. J., French, P. C. \& Merrills, R. J 5hydroxytryptamine uptake by rat brain in vitro. Life Sci. 6 , 1653-1663 (1967)

45. Ross, S. B. \& Renyi, A. L. Inhibition of the uptake of tritiated 5-hydroxytryptamine in brain tissue. Eur. J. Pharm 7, 270-277 (1969).

46. Snyder, S. H. \& Coyle, J. T. Regional differences in $\left[{ }^{3} \mathrm{H}\right]-$ norepinephrine and $\left[{ }^{3} \mathrm{H}\right]$-dopamine uptake in rat brain homogenates. J. Pharmacol. Exp. Ther. 165, 78-86 (1969).

47. Slater, I. H., Rathbun, R. C. \& Kattau, R. Role of 5-hydroxytryptaminergic and adrenergic mechanism in antagonism of reserpine-induced hypothermia in mice. J. Pharm. Pharmacol. 31, 108-110 (1979).

48. Wong, D. T. \& Bymaster, F. P. in Neurochemistry in Clinical Application (eds Tang, L. \& Tang, S.) 77-95 (Plenum, New York, 1995)

49. Wong, D. T., Bymaster, F. P., Horng, J. S. \& Molloy, B. B. 3-(p-trifluoromethylphenoxy)- $N$-methyl-3phenylpropylamine (Lilly 110140), a selective inhibitor of serotonin uptake into synaptosomes of rat brain. Fed. Proc. 33, 296 (1974)

50. Wong, D. T., Bymaster, F. P., Horng, J. S. \& Molloy, B. B. A new selective inhibitor for uptake of serotonin into synaptosomes of rat brain: 3-(p-trifluoromethylphenoxy)$\mathrm{N}$-methyl-3-phenylpropylamine. J. Pharmacol. Exp. Ther. 193, 804-811 (1975)

This was the first full publication to describe fluoxetine as a selective inhibitor of 5-HT uptake in vitro and in vivo.

51. Horng, J. S., Bymaster, F. P. \& Wong, D. T. Effects of compound, Lilly 110140, a specific inhibitor of serotonin uptake on transport of monoamines in peripheral tissues of rat. Fed. Proc. 33, 560 (1974). 
52. Horng, J. S. \& Wong, D. T. Effects of serotonin uptake inhibitor, Lilly 110140 , on transport of serotonin in rat and human blood platelets. Biochem. Pharmacol. 25, 865-867 (1976).

53. Fuller, R. W. \& Perry, K. W. Blockade of 4 chloroamphetamine-induced depletion of brain serotonin by 3 -( $p$-trifluoromethylphenoxy)- $N$-methyl-3-phenylpropylamine hydrochloride (Lilly 110140), a selective inhibitor of uptake by serotonin neurons. Fed. Proc. 33, 255 (1974).

54. Wong, D. T. \& Bymaster, F. P. The comparison of fluoxetine and nisoxetine with tricyclic antidepressants in blocking the neurotoxicity of $p$-chloroamphetamine and 6 -hydroxydopamine in the rat brain. Res. Comm. Chem. Path. Pharmacol. 15, 221-231 (1976).

55. Fuller, R. W. Kinetic studies and effects in vivo of a new monoamine oxidase inhibitor, $N$-[2-(o-chlorophenoxy)ethyl]-cyclopropylamine. Biochem. Pharmacol. 17, 2097-2106 (1968)

56. Mills, J., Kattau, R., Slater, I. H. \& Fuller, R. W. $\mathrm{N}$-substituted cyclopropylamines as monoamine oxidase inhibitors. Structure-activity relationships. Dopa potentiation in mice and in vitro inhibition of kynuramine oxidation. J. Med. Chem. 11, 95-97 (1968).

57. Fuller, R. W. Hines, C. W. \& Mills J. Lowering of brain serotonin level by chloramphetamines. Biochem. Pharmacol. 14, 483-488 (1965).

58. Fuller, R. W. \& Hines, C. W. Tissue levels of chloroamphetamines in rats and mice. J. Pharm. Sci. 56, 302-303 (1967).

59. Fuller, R. W. \& Hines, C. W. Inhibition by pchloroamphetamine of the conversion of 5 hydroxytryptamine to 5-hydroxyindoleacetic acid in rat brain. J. Pharm. Pharmacol. 22, 634-635 (1970).

60. Meek, J. L, Fuxe, K \& Carlsson, A. Blockade of $p$ chloromethamphetamine induced 5-hydroxytryptamine depletion by chlorimipramine, chlorpheniramine and meperidine. Biochem. Pharmacol. 20, 707-709 (1971).

61. Carlsson, A., Jonason, J., Lindqvist, M. \& Fuxe, K. Demonstration of extraneuronal 5-hydroxytryptamine accumulation in brain following membrane-pump blockade by chlorimipramine. Brain Res. 12, 456-460 (1969).

62. Fuller, R. W., Perry, K. W., Snoddy, H. D. \& Molloy, B. B. Comparison of the specificity of $3-(p-$ trifluoromethylphenoxy)- $N$-methyl-3-phenylpropylamine and chlorimipramine as amine uptake inhibitors in mice. Eur. J. Pharmacol. 28, 233-236 (1974).

63. Da Prada, M. \& Pletscher, A. On the mechanism of chlorpromazine-induced changes of cerebral homovanillic acid levels. J. Pharm. Pharmacol. 18, 628-630 (1966).

64. Miller, F. P., Cox, R. H., Snodgrass, W. R. \& Maickel, R. P. Comparative effects of $p$-chloroamphetamine and $p$ chloro- $N$-methylamphetamine on rat brain norepinephrine, serotonin and 5-hydroxyindole-3-acetic acid. Biochem. Pharmacol. 19, 435-442 (1970).

65. Perry, K. W. \& Fuller, R. W. Effect of 3-(ptrifluoromethylphenoxy)- $N$-methyl-3-phenylpropylamine $\mathrm{HCl}$ (Lilly 110140), a specific inhibitor of serotonin uptake, on 5-hydroxyindole levels and turnover in rats. Fed. Proc. 33, 560 (1974).
66. Bymaster, F. P. \& Wong, D. T. Effect of Lilly 110140 , 3-(ptrifluoromethylphenoxy)- $N$-methyl-3-phenylpropylamine on synthesis of [3H]-serotonin from [3H]-tryptophan in rat brain. Pharmacologist 16, 244 (1974).

67. Clemens, J. A., Sawyer, B. D. \& Cerimele, B. Further evidence that serotonin is a neurotransmitter involved in the control of prolactin secretion. Endocrinology $\mathbf{1 0 0}$, 692-698 (1977).

68. Perry, K. W. \& Fuller, R. W. Effect of fluoxetine on serotonin and dopamine concentration in microdialysis fluid from rat striatum. Life Sci. 50, 1683-1690 (1992).

69. Fuller, R. W., Snoddy, H. D. \& Molloy B. B. Potentiation of the L-5-hydroxytryptophan-induced elevation of plasma corticosterone levels in rats by a specific inhibitor of serotonin uptake. Res. Comm. Chem. Path. Pharmacol. 10, 193-196 (1975)

70. Parli, C. J. \& Hick, J. In vivo demethylation of Lilly 110140 : 3 (p-trifluoromethylphenoxy) $-N$-methyl-3-

phenylpropylamine to an active metabolite, Lilly 103947. Fed. Proc. 33, 560 (1974)

71. Fuller, R. W., Perry, K. W. \& Molloy, B. B. Effect of 3-(ptrifluoromethylphenoxy). N.N.methyl-3-phenylpropylamine on the depletion of brain serotonin by 4-

chloroamphetamine. J. Pharmacol. Exp. Ther. 193 793-803 (1975).

This was the first full publication to describe the blockade of $p$-chloroamphetamine-induced depletion of brain 5-HT by fluoxetine, showing its effect as a selective inhibitor of 5-HT uptake in vivo.

72. Asberg, M., Bertilsson, L., Tuck, D., Cronholm, B. \& Sjoqvist, F. Indoleamine metabolites in the cerebrospinal fluid of depressed patients before and during treatment with nortriptyline. Clin. Pharmacol. Ther. 14, 277-286 (1973).

73. Lemberger, L. et al. Pharmacologic effects in man of a specific serotonin-reuptake inhibitor. Science 199 436-437 (1978).

74. Lemberger, L. et al. Fluoxetine, a selective serotonin uptake inhibitor. Clin. Pharmacol. Ther. 23, 421-429 (1978).

75. Wong, D. T., Bymaster, F. P., Reid, L. R. \& Threlkeld, P. G Fluoxetine and two other serotonin uptake inhibitors without affinity for neuronal receptors. Biochem. Pharmacol. 32, 1287-1293 (1983).

76. Montgomery, S. A. Development of new treatments for depression, J. Clin. Psychiatry 46, 3-6 (1985).

77. Wernicke, J. F. The side effect profile and safety of fluoxetine. J. Clin. Psychiatry 46, 59-67 (1985). This report provided a comprehensive review of the side-effect profile and safety of fluoxetine.

78. Beasley, C. M. Jr, Nilsson, M. E., Koke, S. C. \& Gonzales, J. S. Efficacy, adverse events, and treatment discontinuations in fluoxetine clinical studies of major depression: a meta-analysis of the $20-\mathrm{mg} /$ day dose. J. Clin. Psychiatry 61, 722-728 (2000).

79. Bengtsson, B. O., Wiholm, B. E., Myrhed, M. \& Walinder J. Adverse experiences during treatment with zimelidine on special licence in Sweden. Int. Clin. Pharmacol. 9 55-61 (1994).
80. Davidson, J. R. \& Meltzer-Brody, S. E. The underrecognition and undertreatment of depression: what is the breadth and depth of the problem? J. Clin. Psychiatry 60 (Suppl. 7), 4-9 (1999).

81. Ustun, T. B., Ayuso-Mateos, J. L., Chatterii, S., Mathers, C. \& Murray, C. J. Global burden of depressive disorders in the year 2000. Br. J. Psychiatry 184 386-392 (2004).

82. Arias, E. et al. Deaths: final data for 2001. National Vital Statistics Reports (CDC) 52, 1-116 (2003).

83. Stokes, P. E. \& Holtz, A. Fluoxetine tenth anniversary update: the progress continues. Clin. Ther. 19, 1135-1250 (1997)

This publication presents a comprehensive review of the clinical experience of fluoxetine in the treatment of depression and related disorders.

84. Stokes, P. E. Ten years of fluoxetine. Depress. Anxiety 8 (Suppl. 1), 1-4 (1998)

85. Tranter, R., O'Donovan, C., Chandarana, P. \& Kennedy, S. Prevalence and outcome of partial remission in depression. J. Psychiatry Neurosci. 27, 241-247 (2002).

86. Mulrow, C. D. et al. Efficacy of newer medications for treating depression in primary care patients. Am. J. Med. 108, 54-64 (2000).

87. Wernicke, J. F. Safety and side effect profile of fluoxetine. Expert Opin. Drug Saf. 3, 495-504 (2004).

88. Stevens, J. C. \& Wrighton, S. A. Interaction of the enantiomers of fluoxetine and norfluoxetine with human liver cytochromes P450. J. Pharmacol. Exp. Ther. 266, 964-971 (1993)

89. Page, I. H. \& McCubbin, J. W. Serotonin or tenure for the pharmacologist. Circulation 14, 161 (1956).

\section{Acknowledgements}

We dedicate this article to our deceased colleagues, including R. W. Fuller, B. B. Molloy, R. C. Rathbun, D. W. Robertson and P. Stark, for their dedication and contributions to the project that led to the discovery, preclinical and clinical investigations of fluoxetine, and for their friendship during our careers in the Lilly Research Laboratories. In addition, we owe our deepest gratitude to many other collaborators in this successful project, including I. Slater, R. Kraay, L. Lemberger, C. J. Parli, J. S. Wold, D. N. Masica and J. F. Wernicke, along with the technical contributions of J. S. Horng, K. L. Hauser, H. D. Snoddy, L. R. Reid, P. G. Threlkeld, S. H. Luecke, H. Rowe and J. H. Krushinski.

Competing interests statement

The authors declare no competing financial interests.

\section{(9) Online links}

\section{DATABASES}

The following terms in this article are linked online to: OMIM:

http://www.ncbi.nlm.nih.gov/entrez/query.fcgi?db=OMIM anorexia nervosa | bulimia nervosa | obsessive-compulsive disorder | panic disorde

Access to this interactive links box is free online. 